RBMC

ISSN 2447-9071

doi https://doi.org/10.36414/rbmc.v7i19.117
Contato para correspondência: Alessandra Marques Cardoso

E-mail:

alemarquespuc@gmail.com

Conflito de interesse: Não

Financiamento: Recursos próprios

Recebido: 26/11/2021

Aprovado: 07/12/2021

\title{
Interface entre a urocultura, o EAS e o hemograma nas infecções do trato urinário
}

\section{Interface between uroculture, AES and hemogram in urinary tract infections}

Alexandre Henrique Nunes de Moraes', Lidyanne Camelo Feliciano', Rebeca Jacob de Lima', Rizia Jacob de Lima', Alessandra Marques Cardoso 1,2,3

\author{
' Faculdade da Polícia Militar - FPM \\ ${ }^{2}$ Pontifícia Universidade Católica de Goiás - PUC Goiás \\ ${ }^{3}$ Secretaria de Estado da Saúde de Goiás - SES-GO
}

\begin{abstract}
Resumo
As infecções do trato urinário (ITU) são causadas pela colonização bacteriana de um sítio anatômico que deveria ser estéril. Tais infecções podem afetar tanto o trato urinário inferior causando cistite, como o trato urinário superior causando pielonefrite. Este estudo objetivou pesquisar alterações no EAS (elementos anormais e sedimentoscopia) e no leucograma de pacientes com urocultura positiva, e verificar o sexo, a faixa etária e os principais patógenos isolados nas uroculturas realizadas no Laboratório Clínico do Hospital do Policial Militar de Goiás (HPM). Foi realizado um estudo retrospectivo baseado em uma criteriosa análise de dados coletados no Laboratório do HPM, os quais foram extraídos dos resultados dos exames de urocultura, EAS e leucograma, no período compreendido entrejaneiro/2020 ejaneiro/2021. Os dados referentes ao sexo e idade dos indivíduos, bem como os patógenos envolvidos nas infecções também foram pesquisados. Como resultado do estudo, constatou-se que $14,3 \%$ dos pacientes apresentaram resultado positivo para o exame de urocultura, os quais $93,0 \%$ pertenciam ao sexo feminino e 7,0\% ao sexo masculino. Com relação aos uropatógenos isolados, notou-se que Escherichia coli contabilizou 73,7\% das culturas positivas. Houve uma grande sensibilidade no exame de EAS, mais especificamente no nitrito e na leucocitúria, os quais se alteraram concomitantemente com a urocultura em $75,7 \%$ dos casos. Por outro lado, houve uma percepção de que 11,2\% dos pacientes apresentaram alteração no exame de leucograma. Em uma análise geral, 9,1\% dos pacientes apresentaram alteração em ambos os exames analisados. Com isso, concluiu-se que a urocultura se manteve como padrão ouro de diagnóstico para ITU, o nitrito e a leucocitúria, analitos do EAS, podem ser considerados fortes indicativos de dados para o diagnóstico e o leucograma, um fraco indicativo para este fim.
\end{abstract}

Palavras-chave: Infecções urinárias; Escherichia coli; Diagnóstico laboratorial; Nitrito.

\begin{abstract}
Urinary tract infections (UTI) are caused by bacterial colonization of an anatomical site that should be sterile. Such infections may affect both the lower urinary tract causing cystitis, as well the upper urinary tract causing pyelonephritis. This study aimed to investigate changes in the AES (abnormal elements and sedimentoscopy) and white blood cell count of patients with positive urine cultures, and to verify the sex, age group and the main pathogens isolated in urine cultures performed at the Clinical Laboratory of the Hospital do Policial Militar de Goiás (HPM). A retrospective study was carried out based on a careful analysis of data collected at the HPM Laboratory, which were taken from the results of urocuture, AES and white blood cell tests, in the period between January 2020 and January 2021. The data regarding their sex and age, as well as the pathogens involved in the alterations, were also collected. As a result of the study, it was found that $14.3 \%$ of the patients had a positive result for the uroculture test, of which $93.0 \%$ were female and $7.0 \%$ male. Regarding the pathogen species, it was noted that the most relevant was Escherichia coli accounting for $74.1 \%$ of positive cultures. There was great sensitivity in the AES test, more specifically in nitrite and leukocyturia, which changed con-
\end{abstract}


comitantly with urine culture in $75.7 \%$ of cases. On the other hand, there was a perception that $11.2 \%$ of patients had changes in the WBC test. In a general analysis, $9.1 \%$ of the patients presented alterations in both analyzed exams. Thus, it was concluded that uroculture remained the gold standard for diagnosis for UTI. Nitrite and leukocyturia, analytes of the AES, may be considered strong indicatives of data for diagnosis and leukogram, a weak indicative for this purpose.

Keywords: Urinary Tract Infections; Escherichia coli; Clinical Laboratory Techniques; Nitrite.

\section{Introdução}

As infecções do trato urinário (ITU), as quais estão classificadas como as infecções mais comuns que acometem os seres humanos', são causadas pela colonização bacteriana de um sítio anatômico que deveria ser estéril, com exceção da parte distal da uretra, que pode apresentar bactérias aeróbias e anaeróbias, as quais contribuem para proteção contra agentes patogênicos nesta região². As ITU podem ser divididas em dois tipos: infecção das vias urinárias baixa, cistite e/ou uretrite, e alta, pielonefrite 3 .

Três faixas etárias mais afetadas pelas infecções urinárias são recém-nascidos do sexo masculino, por apresentarem alguma deformidade anatômica ou funcional do aparelho urinário, mulheres jovens com vida sexual ativa, por possuírem a uretra menor e mais próxima do ânus, o que as tornam mais sensíveis a este tipo de infecção ${ }^{4}$, e homens entre 50 e 60 anos que possuem algum distúrbio de próstata ${ }^{5}$. Há também muitos fatores que propiciam a ITU, como higiene inadequada, diabetes mellitus, anomalias no aparelho urinário, entre outros ${ }^{6}$.

A urocultura é um método considerado "padrão ouro" para o diagnóstico de ITU, mas outros exames são utilizados para auxiliar na análise destas infecções para que ela seja mais precisa e eficaz' Neste quesito, destaca-se o uso dos Elementos Anormais e Sedimentoscopia (EAS), o qual é composto pela análise física, química qualitativa e microscópica da urina e, o hemograma, com ênfase no leucograma, o qual está relacionado à resposta inflamatória, provocando um aumento do número de leucócitos ${ }^{8-10}$.

Para a realização da urocultura, a amostra de urina considerada adequada é a de jato médio ${ }^{11,12}$. O procedimento consiste na inoculação da amostra de urina em placas com meio seletivo (ágar MacConkey ou ágar Eosin Methylene Blue) e em meio não seletivo (ágar CLED), pelo método de esgotamento de alça e varredura, respectivamente, utilizando a alça calibrada de platina ou de plástico, de diâmetro $0,001 \mathrm{~mL}$ ou $0,01 \mathrm{~mL}$. Os meios de cultura inoculados são incubados entre $35^{\circ} \mathrm{C}$ e $37^{\circ} \mathrm{C}$ durante 18 a 24 horas ${ }^{13}$. Após esse período, é realizada a contagem de colônias bacterianas. $\mathrm{O}$ diagnóstico de ITU será confirmado a partir de uma contagem de colônias igual ou superior a 100.000 UFC/mL de urina ${ }^{14}$.

Os patógenos mais prevalentes nas ITU são as bactérias Gram negativas, estando em primeiro lugar a Escherichia coli, seguida de Klebsiella spp., Enterobacter spp., Acinetobacter spp., Proteus spp. e Pseudomonas spp. Outro importante uropatógeno é o Staphylococcus saprophyticus, um coco Gram positivo, que está mais frequentemente relacionado a quadros de ITU não complicadas. Quando há crescimento de mais de um microrganismo na urocultura, é muito rara a infecção ser verdadeira, pois geralmente esse evento se dá pela contaminação bacteriana, com crescimento de microrganismos como Streptococcus alfa-hemolíticos, Lactobacilos, Gardnerella e espécies de Corynebacterium ${ }^{5,7,15}$.

OEASé um exame muito importante na indicação de infecção urinária ${ }^{16}$. A amostra de urina recomendada é o jato médio, de preferência a primeira do dia $^{17}$. O nitrito e a esterase leucocitária são os marcadores da análise bioquímica, examinados pela fita reagente, com razoável precisão e exatidão comparados com a urocultura quantitativa ${ }^{18}$. Para que o nitrito seja positivo deve haver nitrato na urina, quantidade adequada de bactérias conversoras destes em nitrito e tempo para a conversão?.

Um teste positivo de esterase leucocitária corresponde a aproximadamente 8 a 10 leucócitos por campo de grande aumento ${ }^{7,19}$. A leucocitúria contribui para a triagem de ITU, sendo que a sua contagem no microscópio maior que 10.000 leucócitos/ $\mathrm{mL}$ pode indicar a presença de infecção bacteriana ${ }^{2}$. De acordo com Fonseca et al. ', a maioria das uroculturas positivas, cerca de $78,0 \%$, apresenta correlação positiva com a leucocitúria aumentada (valores superiores a $10.000 / \mathrm{mL}$ ), ressaltando a importância da sedimentoscopia urinária.

O hemograma é um exame que avalia o conjunto de células sanguíneas. Trata-se de um dos testes mais realizados na rotina laboratorial, sendo de grande importância por fornecer informações que são relevantes no diagnóstico de diversas patologias, sejam elas inflamatórias ou infecciosas, dentre outros distúrbios hematológicos. Em casos de infecção, os leucócitos são as principais células sanguíneas que atuam, em conjunto, na defesa do organismo. Logo, a contagem diferencial de leucócitos se torna necessária para nortear o tipo de invasão microbiana ${ }^{20,21}$.

As infecções bacterianas estimulam a produção de neutrófilos ${ }^{22}$, os quais são responsáveis tanto pelo desenvolvimento quanto pela modulação da resposta de inflamações agudas. Estes compõem a barreira do sistema imune e estão em maior quantidade na circulação ${ }^{23}$. A produção e a maturação dos neutrófilos ocorre na medula óssea, a qual pode liberar células imaturas 
dependendo do nível de infecção ${ }^{10}$. Em alguns casos, como, por exemplo, em pacientes transplantados, o número de neutrófilos e a sua função tendem a estar reduzidos devido ao uso de certos tipos de drogas, como os corticosteroides ${ }^{24}$.

Neste cenário, este estudo objetivou pesquisar alterações no EAS e no leucograma de pacientes com urocultura positiva, e verificar o sexo, a faixa etária e os principais patógenos isolados nas uroculturas realizadas no Laboratório Clínico do Hospital do Policial Militar de Goiás.

\section{Métodos}

Este foi um estudo descritivo transversal retrospectivo, no qual foi feita a análise dos resultados de exames de urocultura realizados na seção de Microbiologia, EAS em Líquidos Corporais e hemograma na seção de Hematologia, coletados do banco de dados do Laboratório Clínico do Hospital do Policial Militar de Goiás (HPMGO), em Goiânia-GO. Os exames pesquisados foram realizados entre janeiro/2020 e janeiro/2021, e a coleta em banco de dados foi executada no mês de março/2021 no Laboratório do HPM-GO.

Para a realização dos exames de urocultura e EAS, foi utilizado o jato médio da primeira urina da manhã. Amostras com contagem de colônias igual ou superior a 100.000 UFC/mL foram consideradas positivas. Após o isolamento dos microrganismos, procedeu-se a identificação bioquímica e realizou-se o teste de suscetibilidade aos antimicrobianos.

No EAS foram feitas as análises física, química e microscópica. Foi considerada leucocitúria em amostras de urina com leucócitos acima de 10.000/mL. Para o hemograma, foram utilizadas amostras de sangue periférico coletado em tubo com o anticoagulanteEDTA, sendo considerado leucocitose em amostras com leucócitos acima de 11.000/mm3 e a contagem das células sanguíneas foi realizada a partir de métodos automatizados. Logo em seguida, foi feito o esfregaço sanguíneo em lâmina para avaliação microscópica.

Os dados foram tabelados em planilha eletrônica Excel de acordo com os laudos dos exames emitidos pelo Laboratório do HPM. Esta foi organizada em três abas, correspondendo aos resultados de uroculturas, EAS e leucogramas, respectivamente. Adicionalmente, foram acrescentadas à planilha Excel os seguintes dados dos pacientes: idade e sexo.

Foi resguardada a privacidade e a confidencialidade dos dados dos pacientes, uma vez que os mesmos não foram identificados. Salienta-se que o projeto foi cadastrado na Plataforma Brasil e aprovado pelo Comitê de Ética em Pesquisa do Hospital e Maternidade Dona Íris, sob o parecer número 3.823.710 de 05/02/2020, atendendo às exigências da Resolução 466/12.

No período estudado foram realizadas 858 uroculturas, sendo $735(85,7 \%)$ negativase 123 (14,3\%) positivas. Das uroculturas positivas foram excluídos os resultados de pacientes que não realizaram pelo menos um dos seguintes exames: EAS e/ou hemograma. Dessa forma, foram selecionadas as uroculturas positivas de 114 pacientes, sendo que destas, 77 apresentaram concomitantemente resultados de EAS e hemograma, 34 apenas EAS, e três apenas hemograma.

\section{Resultados}

Das 114 amostras de uroculturas positivas, 106 (93,0\%) pertenciam ao sexo feminino e oito $(7,0 \%)$ ao masculino. Foi calculada a média de idade desses pacientes, observando-se que no sexo feminino a idade variou de 15 a 91 anos, com média de idade igual a 49 anos. Em relação ao sexo masculino, a variação de idade foi de 27 a 85 anos, com média de idade igual a 66 anos. Considerando ambos os sexos, a idade dos pacientes variou de 15 a 91 anos, sendo a média de idade geral equivalente a 50 anos.

Quanto à prevalência dos microrganismos isolados nas uroculturas, observou-se 84 (73,7\%) isolados de Escherichia coli, nove $(7,9 \%)$ de Klebsiella aerogenes, cinco $(4,4 \%)$ de Staphylococcus aureus, três (2,6\%) de Enterococcus spp. e $13(11,4 \%)$ de outros microrganismos, a saber: Acinetobacter baumannii, Citrobacter spp., Enterobacter spp., Klebsiella ozaenae, Klebsiella pneumoniae, Pseudomonas spp., Proteus mirabilis e Staphylococcus saprophyticus.

Do global de 114 pacientes com urocultura positiva, foram obtidos resultados de 111 amostras de EAS. Destes, 84 (75,7\%) tiveram alteração neste exame, sendo que $72(85,7 \%)$ continham leucocitúria acima de $10.000 / \mathrm{mL}$ e 48 (57,1\%) possuíam nitrito positivo, como mostrado na Figura 1. Os resultados da pesquisa da esterase leucocitária no EAS não estavam disponíveis no banco de dados consultado.

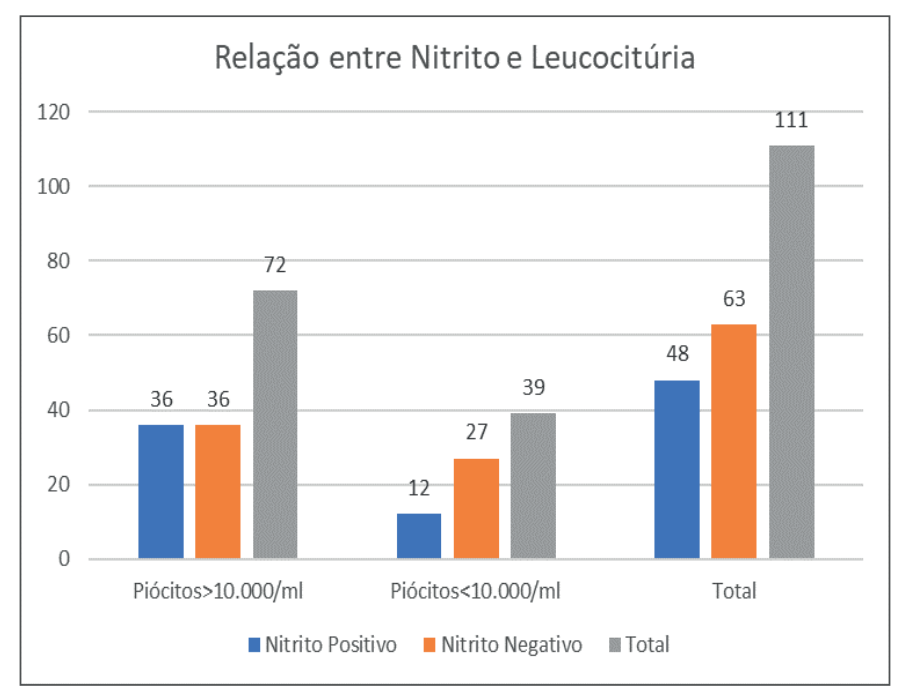

Figura 1. Relação entre nitrito positivo e negativo e a contagem de leucócitos em urinas de pacientes do Laboratório Clínico do HPM-GO, entre janeiro/2020 e janeiro/2021. 
Em relação ao hemograma, 80 pacientes realizaram este exame, sendo que nove $(11,2 \%)$ exames apresentaram número de leucócitos acima de 11.000/. $\mathrm{mm}^{3}$.

Dos pacientes que realizaram EAS e/ou hemograma, 77 $(66,4 \%)$ apresentaram resultados de EAS e hemograma concomitantemente. Destes, sete $(9,1 \%)$ obtiveram alterações em ambos os exames, sendo encontrados no EAS alterações no nitrito e/ou leucocitúria e no hemograma, contagem de leucócitos acima de $11.000 / \mathrm{mm}^{3}$. Nas Figuras 2 e 3 estão apresentadas as relações entre nitrito e leucograma e, leucocitúria e leucograma, respectivamente.

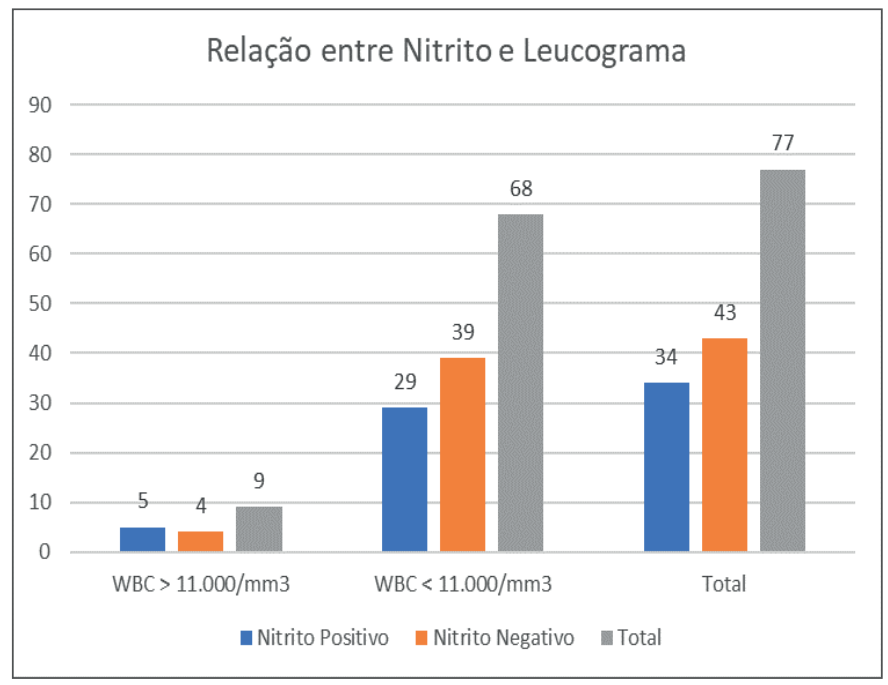

Figura 2. Relação entre nitrito positivo e negativo com a contagem global de leucócitos em hemograma de pacientes do Laboratório Clínico do HPM-GO, entre janeiro/2020 e janeiro/2021.

*Legenda: WBC = Contagem de leucócitos.

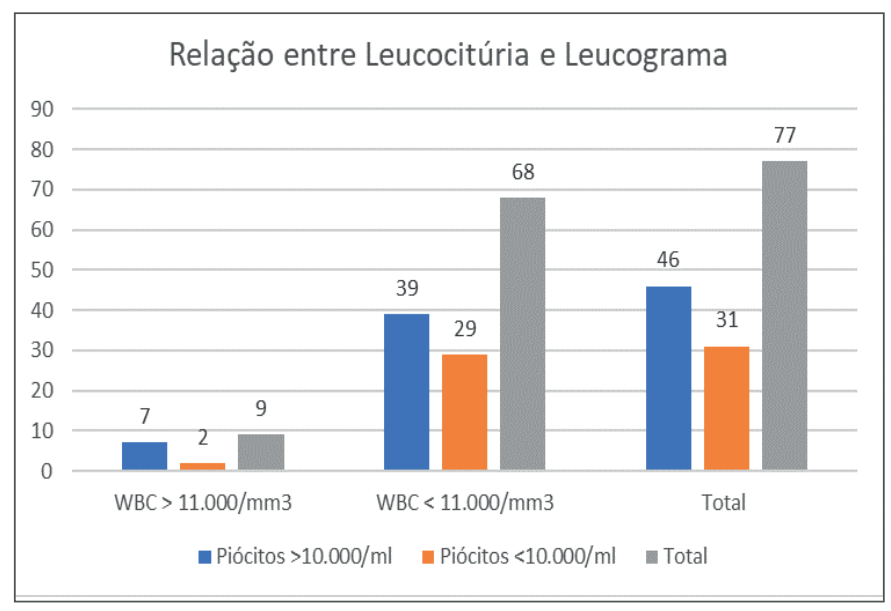

Figura 3. Relação entre contagem de leucócitos urinários e contagem global de leucócitos em hemograma de pacientes do Laboratório Clínico do HPM-GO, entre janeiro/2020 e janeiro/2021.

*Legenda: WBC = Contagem de leucócitos

\section{Discussão}

As ITU podem ser classificadas de acordo com o nível de invasão bacteriana no hospedeiro, sendo elas infecção do aparelho geniturinário baixo e alto, sendo que a primeira apresenta menor comprometimento do hospedeiro ${ }^{25}$. Como apresentado nos resultados, no período estudado, $14,3 \%$ das uroculturas apresentaram resultado positivo para o crescimento de diversos uropatógenos. Nesse quesito, pode-se destacar que a infecção urinária é uma enfermidade de elevada relevância e que deve ser analisada com maior frequência e atenção.

Em relação ao sexo dos pacientes, num total de 114 amostras positivas analisadas, foi observado maior número de positividade para ITU em pacientes do sexo feminino, sendo $93,0 \%$, e menor número de infecção no sexo masculino (7,0\%). O sexo feminino apresenta maior suscetibilidade à aquisição de ITU em razão da anatomia do sistema urinário da mulher, em que a uretra feminina é mais próxima do ânus, facilitando assim a contaminação por bactérias presentes neste sítio anatômico ${ }^{4,25}$.

No que diz respeito à idade, no sexo feminino as ITU prevaleceram em pacientes com média de 49 anos de idade, o que é justificável por apresentarem vida sexual ativa ${ }^{4}$. Já nos homens, a média de idade foi de 66 anos, o que pode estar relacionado com algum distúrbio de próstata ${ }^{5}$, o que é muito prevalente em homens nesta faixa etária e também, por questões de higiene inadequada e outras comorbidades, como por exemplo, o diabetes mellitus ${ }^{6}$.

No presente estudo, observou-se também a elevada prevalência da $E$. coli $(73,7 \%)$, o que não é diferente do observado em outros estudos, como no de Sato et al., o qual apresentou $61,2 \%$ de uroculturas positivas por $E$. coli, prevalecendo a mesma sobre as demais bactérias, bem como no estudo de Malinovski \& Estrillo, onde predominou a E. coli apresentando um percentual de $82,5 \%$ de infecção. Isso ocorre devido ao fato de que esse microrganismo faz parte da microbiota normal do intestino humano, sendo excretado nas fezes. ${ }^{26}$

As infecções urinárias são enfermidades de rápida progressão e agravo, podendo gerar complicações clássicas, chegando até mesmo à sepse, se não tratadas de forma rápida e eficiente ${ }^{24}$. O exame de urocultura realizado no HPM disponibiliza ao médico o perfil de suscetibilidade do microrganismo isolado frente aos antimicrobianos, isto faz com que o tratamento seja eficaz, evitando ou diminuindo a possibilidade do desenvolvimento de resistência antimicrobiana.

O exame de EAS deve ser considerado um exame de triagem, devido ao fato de apresentar correlações significativas com a urocultura, porém deve-se destacar que não é confirmatório para ITU, devido a ocorrências de alterações 
ocasionadas por outros fatores que não ITU. O nitrito, por exemplo, é um marcador importante para nas ITU, porém pode apresentar-se alterado em amostras processadas com um período superior a duas horas após a coleta em temperatura ambiente ou em 24 horas em ambiente refrigerado ${ }^{1,2}$.

Quando analisado o exame de EAS, nota-se um padrão de alterações ligadas à formação da esterase leucocitária, contagem microscópica de leucócitos e conversão do nitrato em nitrito. Como mencionado, de 111 pacientes com urocultura positiva que haviam realizado o exame de EAS, 72 (85,7\%) apresentaram o número de leucócitos na urina aumentado e 48 (43,2\%) resultado positivo para nitrito, apresentando assim, uma alta relação deste exame com a urocultura. Com isso, ressalta-se a importância de um aprofundamento diagnóstico em pacientes que apresentem no exame de EAS alteração em um desses analitos.

O hemograma é um exame composto por três determinações básicas que compreendem as avaliações dos eritrócitos (eritrograma), dos leucócitos (leucograma) e das plaquetas (plaquetograma). Os leucócitos sanguíneos aumentam sua contagem global e diferencial em infecções de um modo geral, sendo os neutrófilos as células responsáveis pelo combate bacteriano, portanto a que aumenta mais expressivamente sua contagem. Devido a isto, o leucograma figura-se como um importante exame no diagnóstico de agravos de ITU, tendo em vista que uma maior quantidade de leucócitos será mobilizada no combate daquele patógeno ${ }^{22}$.

Com relação à utilidade dos resultados do leucograma nas ITU, considerou-se uma baixa relação a partir das análises de dados, tendo em vista que, dos pacientes com urocultura positiva, nove $(11,2 \%)$ apresentaram leucocitose. E dentre os pacientes com alteração nos resultados do leucograma, os isolados bacterianos foram: $E$. coli presente em oito $(88,9 \%)$ amostras e K. aerogenes em uma $(11,1 \%)$ amostra.

De modo geral, notou-se maior relevância do exame de EAS para fins de triagem para ITU, por este apresentar alterações significativas em determinados analitos, como positividade do nitrito e leucocitúria acima de $10.000 / \mathrm{mL}$ em pacientes com urocultura positiva. Já o hemograma, especificamente o leucograma, é um marcador que não apresentou relevância na diagnose de ITU, por apresentar um número baixo de leucocitose em pacientes com urocultura positiva. Porém, nesse mesmo sentido, reafirma-se que, para um diagnóstico mais fidedigno, é necessária a realização da urocultura, tendo em vista que esta figura-se como um método padrão ouro para diagnóstico laboratorial das ITU2,14.

\section{Conclusão}

Concluiu-se que o nitrito e a leucocitúria foram analitos do EAS importantíssimos para investigação de ITU. Estes parâ- metros, porém, não são confirmatórios, sendo considerados exames de triagem. O leucograma foi considerado um marcador de baixa relevância para pacientes com urocultura positiva.

As ITU foram prevalentes no sexo feminino, devido à anatomofisiologia genital feminina, e a média de idade destas pacientes foi equivalente a 49 anos, com variação de idade entre 15 e 91 anos, faixa etária em que as mulheres normalmente apresentam vida sexual ativa. Já no sexo masculino, a média de idade dos pacientes com ITU foi de 66 anos, variando entre 27 e 85 anos, fase em que os homens geralmente possuem distúrbios de próstata e, para ambos os sexos, a média foi de 50 anos.

A E. coli foi o uropatógeno mais frequente, tendo sido isolado em $73,7 \%$ das uroculturas realizadas no HPM e a urocultura manteve-se como padrão ouro para o diagnóstico laboratorial das ITU.

\section{Referências}

1. Fonseca FLA, Santos PM, Belardo TMG, Fonseca ALA, Caputto LZ, Alves BCA, et al. Análise de leucócitos em urina de pacientes com uroculturas positivas. RBAC. 2016;48(3):258-61.

2. Oliveira LCA, Souto RCF. Prevalência de infecção do trato urinário em pacientes ambulatoriais e sua relação com os valores de nitrito e leucócitos. RBAC. 2018;50(3):237-43.

3. Silva CHPM, Lins AP, Souza DR, Cruz CSO, Bergamaschi GC. Desenvolvimento e utilização de conservante químico em amostras de urina para análises microbiológicas (urocultura) e rotina (E.A.S.). RBAC. 2005;37(3):137-147.

4. Costa TS, Cardoso AM. Escherichia coli em uroculturas de pacientes comunitários: prevalência e perfil de suscetibilidade antimicrobiana. RBAC. 2020;52(1):82-6.

5. Heilberg IP, Schor N. Abordagem diagnóstica e terapêutica na infecção do trato urinário - Itu. Rev. Assoc. Med Bras. 2003;49(1):109-16.

6. Tosetto AT. Análise de elementos anormais do sedimento urinário (EAS) e baterioscopia em estudantes universitárias de uma instituição de ensino superior de Sinop - MT. Trabalho de Conclusão de Curso (Graduação em Farmácia). Sinop: Universidade Federal de Mato Grosso, Instituto de Ciências da Saúde. 2018.

7. Sato AF, Svidzinski AE, Consolaro MEL, Boer CG. Nitrito urinário em infecção do trato urinário por cocos gram positivos. J Bras. Patol. Med Lab. 2005;41(6):397-404.

8. Heggendornn LH, Silva NA, Cunha GA. Urinálise: a importância da sedimentoscopia em exames físicoquímicos normais. REB. 2014;7(4):431-443. 
9. Francischetti I, Moreno JB, Scholz M, Yoshida WB. Os leucócitos e a resposta inflamatória na lesão de isquemia-reperfusão. Rev. Bras. Cir. Cardiovasc. 2010;25(4):575-584.

10. Lorenzi TF. Manual de Hematologia Propedêutica e Clínica. 4. ed. Rio de Janeiro: Guanabara Koogan; 2006.

11. Valente SMTB. Estudo sobre colheita de urina para cultura. Rev. Esc. Enf. 1983;7(3):253-274.

12. Angerami ELS, Santesso M, Oliveira BM, Boemer MR. Avaliação da técnica de colheita de urina asséptica em mulheres. Rev. Bras. Enf. 1975;28(1):60-64.

13. Brasil, ANVISA - Principais Síndromes Infecciosas, Módulo I, 2004.

14. Masson LC, Martins LV, Gomes CM, Cardoso AM. Diagnóstico laboratorial das infecções urinárias: relação entre a urocultura e o EAS. RBAC. 2020;52(1):77-81.

15. Malinovski E, Estrillo ALA. Bactérias mais frequentes em infecções do trato urinário. RESMA. 2021;12(1):121-134.

16. Jeff A, Simerville MD, William C, Maxted MD, John J, Pahira MD. Urinalysis: A Comprehensive Review. Am. Fam. Physician. 2005;71(6):1153-1162.

17. Queiroz BVMF. Exame de urina: Uma revisão. Trabalho de Conclusão de Curso (Graduação em Farmácia). Cuité: Centro de Educação e Saúde da Universidade Federal de Campina Grande-Campus Cuité. 2016.

18. Devillé WL, Yzermans JC, Van Duijn NP, Bezemer PD, Van Der Wind DA, Bouter LM. The urine dipstick test useful to rule out infections. A meta-analysis of the accuracy. BMC Urology. 2004; 4:1-14.

19. Barros E, Manfro RC, Thomé F, Gonçalves LF. Nefrologia: rotinas, diagnóstico e tratamento. 2a ed. Artmed. 1999;4:59-61.

20. Moreira CLG, Oliveira MC, Alves FEF, Correia FMA. A importância da realização do hemograma para triagem de anemias em pessoas da terceira idade: uma revisão bibliográfica. Temas em Saúde. 2020;20(6):7-24.

21. Santos JS. Análise do leucograma como preditor de mortalidade na infecção presumida e na sepse. Dissertação (Mestrado em Saúde e Meio Ambiente). Univille: Universidade da região de Joinville. 2019.

22. Mota IS, Castro FFS. Relação da reação leucemoide neutrofílica com doenças infecciosas. Monografia (Graduação em Biomedicina). Faculdade de Educação e Ciências da Saúde, Centro Universitário de Brasília, 2020.

23. Silva IC. Neutrófilos: aspectos clássicos, plasticidade e novas funções imunorregulatórias. Rev. Interdisciplin. Estud. Exp. Anim. Hum. 2015;7:35-46.

24. David CMN. Infecção em UTI. Ribeirão Preto,
Simpósio: Medicina Intensiva: I. Infecção e Choque. 1998;(31):337-348.

25. Lopes HV, Tavares W. Diagnóstico das infecções do trato urinário. Rev. Assoc. Med. Bras. 2005;51(6).

26. Drumond SN, Santiago AF, Moreira M, Lanna MCS, Roeser HMP. Identificação molecular de Escherichia coli diarreiogênica na Bacia Hidrográfica do Rio Xopotó na região do Alto Rio Doce. Eng. Sanit. Ambient. 2018;23(3):579-590. 